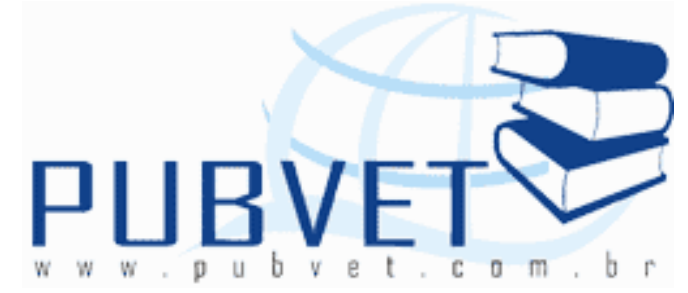

PUBVET, Publicações em Medicina Veterinária e Zootecnia.

\title{
Mudanças climáticas e impacto na produção animal
}

Edson Júnior Heitor de Paula ${ }^{1}$, Elias Nunes Martins², Cláudio de Ulhôa Magnabosco ${ }^{3}$, Luiz Juliano Valerio Geron ${ }^{4}$, Samuel Laudelino Silva ${ }^{1}$, Eurico Lucas de Souza Neto ${ }^{4}$

${ }^{1}$ Doutorando em Zootecnia na Universidade Estadual de Maringá, Professor da UNEMAT, Campus Pontes e Lacerda, Departamento de Zootecnia, BR 174, km 209, CP 181, Pontes e Lacerda, MT, CEP 78250000.

2 Universidade Estadual de Maringá, Maringá, PR.

${ }^{3}$ Embrapa Cerrados/Arroz e Feijão, Goiânia, GO.

4 Universidade do Estado de Mato Grosso - UNEMAT, Campus de Pontes e Lacerda, MT.

\section{Resumo}

A concentração de gases de efeito estufa tem aumentado na atmosfera e provocado um aquecimento anormal da superfície terrestre. Simulações de cenários projetam aumento de 2 a $6^{\circ} \mathrm{C}$ na temperatura média do ar até o ano de 2100. Várias são as causas desse aumento sendo algumas de fontes antrópicas, dentre elas o setor pecuário. O Brasil tem posição de destaque na produção pecuária mundial, pois possui o maior rebanho comercial bovino é o sexto maior produtor de leite e terceiro maior produtor de suínos. Toda essa produção vem acompanhada de críticas da comunidade internacional, pois um bovino adulto produz em média $57 \mathrm{~kg}$ de metano entérico anualmente, e esse 
PAULA, E.J.H. et al. Mudanças climáticas e impacto na produção animal. PUBVET, Londrina, V. 6, N. 30, Ed. 217, Art. 1445, 2012.

gás é 25 vezes mais poluente que o $\mathrm{CO}_{2}$. As críticas sobre a suinocultura estão voltadas para o tratamento dos dejetos que muitas das vezes são mal acondicionados em esterqueira ao ar livre que liberam metano e óxido nitroso, este último 296 vezes mais poluente que $0 \mathrm{CO}_{2}$. Outro fator que agrava a conta do setor pecuário é o desmatamento que na maioria das vezes ocorre para a implantação de pastagens. A derrubada da floresta que tem maior potencial de sequestro de carbono que as pastagens já é um fator que se agrava com a queimada ou decomposição da matéria orgânica liberando gás carbônico. As temperaturas mais elevadas também trarão prejuízos para a produção animal em regiões de clima tropical, pois temperaturas acima da zona de termoneutralidade dos animais afetam o consumo de alimentos diminuindo consequentemente a produção dos mesmos.

Palavras-chave: Aquecimento global, pecuária, agricultura, suprimento de alimentos

\section{Climate change and impact on animal production}

\section{Abstract}

The concentration of greenhouse gases in the atmosphere has increased and caused an abnormal warming of the earth's surface. Simulations of scenarios projected increase of 2 to $6^{\circ} \mathrm{C}$ in mean air temperature by the year 2100 . There are many causes of this increase being some of anthropogenic sources, among them the livestock sector. Brazil has a prominent position in world livestock production, it has the largest commercial cattle herd is the sixth largest milk producer and third largest producer of swine. All this production is accompanied by criticism from the international community as a mature cow produces on average $57 \mathrm{~kg}$ of enteric methane annually, and this gas is 25 times more polluting than $\mathrm{CO} 2$. The criticisms are focused on the hog for the treatment of waste that often are poorly packed in dunghill outdoor release methane and nitrous oxide, the latter 296 times more polluting than CO2. Another factor that aggravates the account of the livestock sector is the 
PAULA, E.J.H. et al. Mudanças climáticas e impacto na produção animal. PUBVET, Londrina, V. 6, N. 30, Ed. 217, Art. 1445, 2012.

deforestation that occurs most often for the implantation of pastures. The felling of the forest that has the greatest potential for carbon sequestration that pasture is already a factor that worsens the burning or decomposition of organic matter releasing carbon dioxide. Warmer temperatures also bring losses to livestock production in tropical regions, for temperatures above the thermoneutral zone of animals affect the consumption of foods thereby decreasing the production of the same.

Keywords: Global warming, livestock, agriculture, food supply

\section{INTRODUÇÃO}

O efeito estufa natural é um condicionante para a vida na superfície terrestre, pois mantêm a atmosfera da Terra por volta de $30^{\circ} \mathrm{C}$ mais quente do que seria sem a existência dele. Entretanto, aumentos recentes nas concentrações dos gases metano $\left(\mathrm{CH}_{4}\right)$, dióxido de carbono $\left(\mathrm{CO}_{2}\right)$, monóxido de carbono $(\mathrm{CO})$, óxido nitroso $\left(\mathrm{N}_{2} \mathrm{O}\right)$, óxidos de nitrogênio $\left(\mathrm{NO}_{x}\right)$ e ozônio $\left(\mathrm{O}_{3}\right)$ na atmosfera, devido à atividade antrópica, em grande parte associada a países mais desenvolvidos, têm causado impacto no balanço de radiação solar do Planeta, tendendo ao aquecimento da superfície terrestre (Lima, 2002).

A mudança global do clima devido ao aquecimento anormal da superfície terrestre tem provocado discussões em todo o mundo nas mais diversas áreas, prevê-se aumento do nível dos oceanos, mudanças no padrão de evaporação, na maior ocorrência de eventos extremos como chuvas intensas, tempestades tropicais e fenômenos relacionados às ressacas marítimas, porém o setor agropecuário, dada sua importância para a produção de alimentos e devido a sua dependência direta dos fatores climáticos (temperatura, pluviosidade e etc.) tem despertado grande interesse de muitos pesquisadores que tem sensibilizado políticos e organizações não governamentais sobre a necessidade da mitigação deste efeito. Segundo Thomas et al. (2004), com a elevação das temperaturas, no cenário de menor mudança climática prevista, cerca de 18 
PAULA, E.J.H. et al. Mudanças climáticas e impacto na produção animal. PUBVET, Londrina, V. 6, N. 30, Ed. 217, Art. 1445, 2012.

espécies vegetais estarão ameaçadas de extinção até o ano de 2050, além de algumas espécies animais.

Diante dos problemas sociais, econômicos e ambientais que esse aquecimento global pode trazer para as sociedades a Organização Meteorológica Mundial (OMM) e o Programa das Nações Unidas para o Meio Ambiente (PNUMA) criaram o Painel Intergovernamental sobre Mudanças Climáticas (IPCC) em 1988, com a finalidade de realizar análises sistemáticas sobre o conhecimento científico existente, sobre as mudanças climáticas globais, seus impactos potenciais e as opções de mitigação e adaptação (IPCC, 2001).

Estima-se que, se a taxa atual de aumento de gases de efeito estufa continuar pelo próximo século no Planeta, as temperaturas médias globais subirão $0,3^{\circ} \mathrm{C}$ por década, com uma incerteza de $0,2^{\circ} \mathrm{C}$ a $0,6^{\circ} \mathrm{C}$ por década, indicando que é bastante provável que se verifique um aumento de 2 a $6^{\circ} \mathrm{C}$ na temperatura média do ar até o ano de 2100 (Lima, 2002).

Segundo Lima et. al. (2001) nas previsões de longo prazo, as regiões tropicais e sub-tropicais seriam as mais afetadas pela mudança do clima. Aponta-se também que países em desenvolvimento poderão ser mais vulneráveis às alterações climáticas, devido às economias de baixo capital, à deficiência de mercados, à predominância de atividades agrícolas, entre outros fatores.

O Brasil, fazendo parte dos países em desenvolvimento, com sua dimensão continental, possui uma considerável heterogeneidade climática, tipos de solo e topografia. Considerando-se os prognósticos de aumento das temperaturas, pode-se admitir que as regiões climaticamente limítrofes àquelas de delimitação de cultivo adequado de plantas agrícolas se tornarão desfavoráveis ao desenvolvimento vegetal. No caso de baixas temperaturas, regiões que atualmente são limitantes ao desenvolvimento de culturas suscetíveis a geadas, com o aumento do nível térmico decorrente do 
PAULA, E.J.H. et al. Mudanças climáticas e impacto na produção animal. PUBVET, Londrina, V. 6, N. 30, Ed. 217, Art. 1445, 2012.

aquecimento global, passarão a apresentar condições favoráveis ao desenvolvimento de vegetações (Assad et al., 2004).

No caso dos animais domésticos o aquecimento global pode contribuir para o bem estar animal quando consideramos regiões de clima temperado, porém por outro lado pode dificultar ainda mais a utilização de determinados animais que possuam sua zona de conforto térmico inferior às temperaturas médias encontradas nas regiões tropicais.

Esta revisão realizada na disciplina seminários tem o objetivo de abordar o problema da mudança do clima que afeta o setor agropecuário, da contribuição da agricultura e pecuária ao efeito estufa, e ao mesmo tempo apresentar as opções de mitigação das emissões causadas por essas atividades.

\section{DESENVOLVIMENTO DO TEMA}

\section{1 - A ação da temperatura sobre o consumo de alimentos e a produção de alguns animais domésticos}

O componente do clima de maior importância para a produção animal é a temperatura porque exerce ação acentuada sobre as duas classes que encerram maior número de espécies domésticas, mamíferos e aves. Os animais dessas classes são homeotérmicos, isto é, são animais que tem a habilidade de controlar sua temperatura corporal dentro de uma faixa estreita, quando expostos a grandes variações de temperatura (Medeiros e Vieira, 1997). Os mesmos autores relatam que a temperatura ótima para a vida dos homeotérmicos seria a de $20^{\circ} \mathrm{C}$, que corresponde a temperatura crítica abaixo ou acima do qual o animal requer aumentar ou diminuir a produção de calor, equivalente ao conforto fisiológico. Relata ainda que os monogástricos ficam restritos à estreita faixa de neutralidade em torno de $20^{\circ} \mathrm{C}$, enquanto que os poligástricos dispõem de amplos espaços de termoneutralidade, desde 10 até 
PAULA, E.J.H. et al. Mudanças climáticas e impacto na produção animal. PUBVET, Londrina, V. 6, N. 30, Ed. 217, Art. 1445, 2012.

$28^{\circ} \mathrm{C}$, variando entre as espécies e raças de acordo com seus recursos fisiológicos.

Lana et al. (2000) descreve que a temperatura ambiente é considerada o fator físico de maior efeito no desempenho de frangos de corte, já que exerce grande influência no consumo de ração e, com isto, afeta diretamente o ganho de peso e a conversão alimentar destes animais. Neste estudo as aves submetidas a temperaturas ambientais mais elevadas, fora da zona de termoneutralidade, apresentaram peso $15 \%$ inferior ao grupo controle. Ao elevar a temperatura corporal, em função de aumento na temperatura ambiental, as aves aumentam a freqüência respiratória e reduzem o consumo de ração, na tentativa de manter a temperatura corporal dentro de limites fisiológicos.

Em bovinos de leite Silva et al. (2002) avaliando os efeitos da climatização de ambientes em condições de pré-ordenha em animais da raça Holandesa no Instituto de Zootecnia verificaram aumento de $7,28 \%$ na produção de leite; os autores atribuem este aumento ao maior conforto térmico para os animais que propiciou uma maior ingestão de alimentos. Comportamento semelhante é observado para todos os animais domésticos, pois a ingestão de alimentos dá início aos processos metabólicos que produzem aumento da temperatura corporal, logo em animais sob estresse térmico o consumo de alimentos cai.

O aquecimento global demandará maiores investimentos no controle de temperatura nas instalações, principalmente para os monogástricos sob pena de causar maior estresse térmico nos animais que estiverem na zona tropical diminuindo a produção desses e possivelmente animais em zonas temperadas serão beneficiados com a temperatura ambiente se aproximando mais da zona de termoneutralidade. 
PAULA, E.J.H. et al. Mudanças climáticas e impacto na produção animal. PUBVET, Londrina, V. 6, N. 30, Ed. 217, Art. 1445, 2012.

\section{2 - A Produção de ruminantes e o Efeito estufa}

O Brasil ocupa posição de destaque na produção pecuária, sendo importante fornecedor de proteína animal para a população mundial. Atualmente o país possui o maior rebanho comercial bovino, com 197,28 milhões de cabeças e é o segundo maior exportador, apresentando ainda expectativa de aumento de sua produção em 2\% em 2012 atingindo 9,2 milhões de toneladas de equivalente carcaça (USDA, 2011), é também o $6^{\circ}$ maior produtor de leite (FAO, 2009). Apesar da sua importância a pecuária brasileira, em especial, vem sendo criticada por emitir quantidades significativas de gases de efeito estufa (GEE), devido aos seus baixos índices zootécnicos, demandando um volume muito grande de animais e áreas de pastagens para uma baixa produção.

A produção de $\mathrm{CH}_{4}$ é parte do processo digestivo dos herbívoros ruminantes como bovinos, ovinos, bubalinos e caprinos e ocorre no rúmen. A fermentação que ocorre durante o metabolismo dos carboidratos do material vegetal ingerido é um processo anaeróbio efetuado pela população microbiana ruminal, que converte os carboidratos celulósicos em ácidos graxos de cadeia curta, principalmente ácidos acético, propiônico e butírico. Nesse processo digestivo, parte do carbono é concomitantemente transformada também em $\mathrm{CO}_{2}$. A emissão de $\mathrm{CH}_{4}$ varia entre $4 \%$ e $9 \%$ da energia bruta do alimento ingerido, e a média encontrada é de $6 \%$. As emissões globais desse gás geradas a partir dos processos entéricos é considerada a terceira maior fonte em escala global, são estimadas 80 milhões de toneladas anuais, correspondendo a cerca de $22 \%$ das emissões totais de metano geradas por fontes antrópicas (Estados Unidos, 2000).

O gás metano apresenta potencial de aquecimento global 25 vezes maior que o $\mathrm{CO}_{2}$ e tempo de vida na atmosfera de 9 a 15 anos, sendo sua taxa de crescimento anual de 7,0\% (IPCC, 2006). 
PAULA, E.J.H. et al. Mudanças climáticas e impacto na produção animal. PUBVET, Londrina, V. 6, N. 30, Ed. 217, Art. 1445, 2012.

Do metano produzido por fermentação entérica no rúmen, $95 \%$ é excretado por eructação, e daquele produzido no trato digestivo posterior, $89 \%$ é excretado através da respiração e apenas $11 \%$ pelo ânus (Murray et al., 1976).

Um bovino e ovino tem a capacidade de produzir anualmente de 39,1 a $109,5 \mathrm{~kg}$ e de 6,5 a 14,4 kg de metano, respectivamente. A Índia e o Brasil lideram o ranking mundial de emissão total de metano entérico, com 14,5 e 10,3 $\mathrm{Tg}$ de $\mathrm{CH}_{4} /$ ano, respectivamente (Machado et al., 2011).

De acordo com Primavesi et al. (2004) somente os bovinos de corte e de leite somam $96 \%$ das emissões de metano provenientes da fermentação entérica da pecuária do país. As outras categorias de animais (bubalinos, muares, caprinos, asininos, eqüinos, suínos) são responsáveis pelos $4 \%$ restantes das emissões de metano. Os suínos são animais monogástricos e as suas emissões são consideradas negligenciáveis ( $1 \mathrm{~kg} \mathrm{CH}$ /animal/ano).

Pesquisas realizadas com o objetivo de medir a produção de $\mathrm{CH}_{4}$ ruminal por bovinos leiteiros mantidos em pastagens tropicais brasileiras revelaram que a emissão de $\mathrm{CH}_{4}$ por bovinos sem restrição de alimentos baseados em forrageiras tropicais é superior à de bovinos alimentados com forrageiras de clima temperado; a categoria animal, nível de produção e ingestão de forrageiras interfere na produção do gás e animais zebuínos podem gerar mais $\mathrm{CH}_{4}$ que bovinos de sangue europeu (Primavesi et al., 2004).

\section{3 - Estratégias mitigadoras da produção de metano}

No Brasil, a maior parte das emissões de metano provém de áreas extensivas de pastagem (Lima et. al., 2001). O investimento na recuperação de pastagens degradadas seria uma estratégia mitigadora de impacto. De acordo com o relatório da FAO (2009), as pastagens (nativas e cultivadas) representam a segunda maior fonte potencial global de sequestro de carbono (C), com capacidade de drenar da atmosfera 1,7 bilhão de toneladas por ano, 
PAULA, E.J.H. et al. Mudanças climáticas e impacto na produção animal. PUBVET, Londrina, V. 6, N. 30, Ed. 217, Art. 1445, 2012.

ficando atrás somente das florestas, cuja capacidade estimada chega a 2 bilhões de $\mathrm{t}$ de $\mathrm{C}$ por ano. $\mathrm{O}$ uso de práticas de manejo adequadas em pastagens, sobretudo de reposição da fertilidade do solo, possibilita o acúmulo de $C$ no solo a uma taxa de 0,3 t de C/ha/ano (IPCC, 2001), o que corresponde, aproximadamente, à mitigação de $1,1 \mathrm{t}$ de $\mathrm{CO}_{2}$ equivalente/ha/ano. Esse valor, bastante conservador, seria suficiente para anular cerca de $80 \%$ da emissão anual de metano de um bovino de corte adulto, estimada em $57 \mathrm{~kg}$. Pastagens consorciadas a culturas ricas em proteínas podem vir a ser uma opção.

As emissões de metano podem ser reduzidas por meio da melhoria da digestão fermentativa no rúmen. A suplementação alimentar do gado a pasto com proteínas é frequentemente um fator limitante para grande parte das propriedades rurais. Alternativas alimentares devem ser investigadas, em função dos recursos naturais, condições climáticas e estrutura socioeconômica específicas de cada região (Lima, 2002).

Outra estratégia para a redução das emissões de metano é o uso de antibióticos e outros aditivos, pois podem ajudar no melhoramento da eficiência dos processos microbianos visando a otimização da digestão de fibras no rúmen e síntese microbiana. Combinações, tratamentos e bioengenharia de alimentos são oportunidades a serem exploradas. Estudo para a caracterização e identificação dos microorganismos ruminais que produzem metano (Attwood et al., 2008) já está em desenvolvimento e é condição sine qua non para o desenvolvimento de estratégias de mitigação da emissão de metano entérico. Outras possibilidades incluem o desenvolvimento de organismos que oxidam metano ou outros sumidouros de hidrogênio no rúmen, usando engenharia genética, o sequenciamento de seus genomas fornecerá importantes informações que indicarão os alvos mais adequados para estratégias mitigadoras (Buddle et al., 2010). 
PAULA, E.J.H. et al. Mudanças climáticas e impacto na produção animal. PUBVET, Londrina, V. 6, N. 30, Ed. 217, Art. 1445, 2012.

\section{4 - A produção de suínos e o aquecimento global}

O rebanho brasileiro de suínos no ano de 2010 continha 38,957 milhões de unidades, e o estado de Santa Catarina continha o maior efetivo de suínos dos estados da federação com 20,1\%, sendo que a Região Sul representava $47,9 \%$ do efetivo nacional (IBGE, 2010). Em 2011 o Brasil foi o terceiro maior produtor de suínos com 3,295 milhões de toneladas de equivalente carcaça, perdendo apenas para a China e a União Européia (USDA, 2011). Essa elevada produção de carne suína vem acompanhada do aumento de produção dos dejetos que geralmente são líquidos e acondicionados em esterqueiras ou lagoas convencionais onde parte do nitrogênio e carbono pode ser perdida para a atmosfera na forma de amônia $\left(\mathrm{NH}_{3}\right)$ e de GEE.

Considerando uma produção média diária de dejetos líquidos de 7 litros por animal (Oliveira, 2004), são gerados diariamente no Brasil 272,699 milhões de $\mathrm{m}^{3}$ de dejetos, um elevado passivo ambiental, que por outro lado representa a possibilidade de economizar fertilizantes sintéticos na agricultura.

Os principais problemas ambientais observados durante 0 armazenamento dos dejetos na forma líquida, em lagoas e em esterqueiras anaeróbias, referem-se à emissão para a atmosfera de $\mathrm{CH}_{4}$ e $\mathrm{NH}_{3}$, além de maus odores, resultantes da fermentação de compostos nitrogenados por bactérias.

O nitrogênio é o nutriente presente em maior concentração nos dejetos de suínos onde, após o seu armazenamento sob condições anaeróbias, a maior proporção do $\mathrm{N}$ pode ser encontrada na forma amoniacal. Durante a oxidação do $\mathrm{N}$ amoniacal até $\mathrm{NO}_{3}$ por bactérias nitrificadoras e durante a redução do $\mathrm{NO}_{3}$ por bactérias desnitrificadoras ocorre a produção de $\mathrm{N}_{2} \mathrm{O}$ o qual pode ser emitido à atmosfera, potencializando o efeito estufa, além de reagir com ozônio. $\mathrm{O} \mathrm{N}_{2} \mathrm{O}$ é um potente gás de efeito estufa, com potencial de aquecimento global 296 vezes superior ao $\mathrm{CO}_{2}$ (Damasceno, 2010). 
PAULA, E.J.H. et al. Mudanças climáticas e impacto na produção animal. PUBVET, Londrina, V. 6, N. 30, Ed. 217, Art. 1445, 2012.

Uma alternativa para diminuir a contribuição da criação de suínos para o aquecimento global tem sido a utilização de biodigestores que são cogeradores para produção de energia elétrica. Para Amaral (2004), o uso energético do biogás é uma medida fundamental para mitigar o efeito estufa, pois, evita que o metano seja lançado na atmosfera, já que, com a combustão, o metano é transformado em $\mathrm{CO}_{2}$, e este, como gás de efeito estufa, tem poder 21 vezes menor que o metano. Realizando a combustão do metano, reduz-se a poluição atmosférica, gera energia e ainda possibilita a venda de créditos de carbono no mercado internacional.

Outra alternativa encontrada para a diminuição dos impactos ambientais, é o manejo de dejetos de suínos na forma sólida (concentração de matéria seca superior a 60\%), utilizando-se a compostagem ou sistemas de produção sobre cama. O manejo dos dejetos suínos na forma sólida ocasiona diminuição do teor de água dos dejetos e dos odores provocados pelo atual sistema de armazenamento, por se tratar de um processo aeróbio, no qual o principal produto da degradação dos resíduos orgânicos é o $\mathrm{CO}_{2}$. Com o objetivo de comparar o perfil de emissão de $\mathrm{CO}_{2}, \mathrm{CH}_{4}$ e gás sulfídrico $\left(\mathrm{H}_{2} \mathrm{~S}\right)$ do manejo de dejetos suínos nas formas sólida (compostagem) e líquida (esterqueira) Sarda et al. (2010) encontraram redução de 7 vezes na emissão de $\mathrm{CH}_{4}$ quando da utilização da compostagem em comparação a forma líquida, a emissão de $\mathrm{CO}_{2}$ representou $78,5 \%$ do carbono total mineralizado. A emissão de $\mathrm{H}_{2} \mathrm{~S}$ foi expressiva apenas no manejo dos dejetos na forma líquida, desta forma puderam afirmar que o manejo dos resíduos na forma sólida é uma alternativa para a redução dos impactos ambientais pela mitigação do efeito estufa e pela redução de odores.

\section{5 - O Desmatamento e o efeito estufa}

Uso da terra nas várias partes do mundo tem mudado continuamente, normalmente em resposta a demanda competitiva entre os usuários. Alterações no uso da terra têm um impacto nos fluxos de carbono e muitas das 
PAULA, E.J.H. et al. Mudanças climáticas e impacto na produção animal. PUBVET, Londrina, V. 6, N. 30, Ed. 217, Art. 1445, 2012.

mudanças de uso da terra envolvem a produção de gado, quer ocupando terras como pasto ou terras aráveis para produção de forragens.

Uma floresta contém mais carbono do que um campo de culturas anuais ou pastagens, e por isso, quando florestas são cortadas ou, pior, queimadas, grande quantidades de carbono são liberadas a partir da vegetação e do solo para a atmosfera. A redução nos estoques de carbono é complexa: o desmatamento da floresta pode produzir um padrão de complexidade de fluxos líquidos que mudam de direção ao longo do tempo (IPCC, 2001). O cálculo de fluxos de carbono devido a conversão de florestas é, em muitas maneiras, a mais complexa conta a ser realizada sobre as emissões dos gases do efeito estufa. As estimativas das emissões de desmatamento podem variar devido a várias incertezas: as taxas de desmatamento anual da floresta, o destino da terra limpa, as quantidades de carbono contidas em diferentes ecossistemas, os modos como o $\mathrm{CO}_{2}$ é liberado (por exemplo, queima ou decomposição).

A América Latina foi identificada como a região onde está acontecendo a maior expansão de pastagens e de terras aráveis, principalmente à custa de área florestal. O estudo realizado por Asner et al. (2003) mostrou que a maioria das áreas desmatadas viram pastagens para criação de gado é provavelmente e o motivo primordial do desmatamento.

Além de aumentar as emissões de $\mathrm{CO}_{2}$ para a atmosfera, a conversão de terras também pode afetar negativamente outras emissões. Mosier et al. (2004), por exemplo, observou que após a conversão de floresta para pastagem, a oxidação de $\mathrm{CH}_{4}$ por microrganismos do solo é normalmente muito reduzida principalmente devido a compactação do solo ocorrida pelo pisoteio do gado.

O estudo de Asner et al. (2003) na Argentina revelou que em áreas de pastagens degradadas houve um declínio de 25 a $80 \%$ em carbono orgânico do solo, essa perda se dá pela degradação da matéria orgânica em decomposição e erosão; ou seja, existe uma significativa emissão de $\mathrm{CO}_{2}$ 
PAULA, E.J.H. et al. Mudanças climáticas e impacto na produção animal. PUBVET, Londrina, V. 6, N. 30, Ed. 217, Art. 1445, 2012.

líquido nessas áreas fatores que desencadeiam a desertificação. Assumindo uma perda de 8-12 toneladas de carbono no solo por hectare em uma área de terras degradadas de 1 bilhão de hectares (UNEP, 1991), a perda total seria a histórica quantidade de 8-12 bilhões de toneladas de carbono no solo. Da mesma forma, degradação da vegetação acima do solo conduziu a uma perda de carbono estimado de 10-16 toneladas por hectare, um total histórico de 1016 bilhões de toneladas. Assim, a perda total de $C$ como uma conseqüência da desertificação pode ser 18-28 bilhões de toneladas de carbono (FAO, 2009). Contribuição do gado a este total é difícil de estimar, mas é, sem dúvida, alta: pecuária ocupa cerca de dois terços da superfície terrestre seca, e a taxa de desertificação em áreas de pastagem é a maior entre todos os outros usos da terra (3,2 milhões de hectares por ano, contra 2,5 milhões hectares por ano para lavouras (UNEP, 1991).

\section{CONCLUSÃO}

O aquecimento global poderá provocar mudanças no setor agropecuário que também é um dos importantes emissores dos gases de efeito estufa (GEE). Alternativas mitigadoras de GEE como a recuperação de pastagens degradadas, utilização de dietas mais adequadas para ruminantes, inclusão de antibióticos nessas dietas, melhoria dos manejos da criação poderão aumentar a produtividade da pecuária diminuindo o desmatamento devido a menor demanda de novas áreas para a produção animal. A utilização de biodigestores é uma alternativa para diminuir o impacto ambiental de dejetos dos animais e é uma oportunidade de geração de renda para os produtores pela geração de energia e venda de créditos de carbono.

\section{REFERÊNCIAS}

AMARAL, F. L. M. Biodigestão anaeróbia dos resíduos sólidos urbanos: um panorama tecnológico atual. 2004. 108 p. Dissertação (Mestrado Tecnologia Ambiental)- Instituto de Pesquisa Tecnológica do Estado de São Paulo, São Paulo, 2004. 
ASNER, G.P., BORGHI, C.E. OJEDA, R.A. 2003. Desertification in central Argentina: Changes in ecosystem carbon and nitrogen from imaging spectroscopy. Ecological Application, 13(3): 629-648.

ASSAD, E.D; PINTO, H.S; ZULLO JUNIOR, J.; AVILA, A.M.H. Impacto das mudanças climáticas no zoneamento agroclimático do café no Brasil. Pesq. Agropec. Bras., v.39, n. 11, p. 10571064, 2004.

ATTWOD, G. T.; KELLY, W. J.; ALTERMANN, E. H.; LEAHY, S. C. Analysis of the Methanobrevibacter ruminantium draft genome: understanding methanogen biology to inhibit their action in the rumen. Australian Journal of Experimental Agriculture, v. 48, p. 83-88, 2008.

BUDDLE, B. M.; DENIS, M.; ATTWOOD, G. T.; ALTERMANN, E.; JANSSEN, P. H.; RONIMUS, R. S.; PINARES-PATIÑO, C. S.; MUETZEL, S.; WEDLOCK, D. N. Strategies to reduce methane emissions from farmed ruminants grazing on pasture. Veterinary Journal, v. 188, p. 11-17, 2011.

DAMASCENO, F. Injeção de dejetos líquidos de suínos no solo e inibidor de nitrificação como estratégias para reduzir as emissões de amônia e de óxido nitroso. Dissertação (Mestrado Ciência do Solo) - Universidade Federal de Santa Maria, Santa Maria, 2010.

ESTADOS UNIDOS. Enviromental Protection Agency. Evaluating ruminant livestock efficiency projects and programs. In: PEER review draft. Washington: Enviromental Protection Agency, 2000. 48p.

FAO - Food and Agriculture Organization of the United Nations. The State of Food and Agriculture. Livestock in the balance. Roma: FAO, 2009. 166 p. Disponível em: http://www.fao.org/docrep/012/i0680e/i0680e.pdf Acesso em: 18 abril. 2012.

IBGE - Instituto Brasileiro de Geografia e Estatística. Produção da Pecuária Municipal. 2010. Rio de Janeiro, v. 38, 65p, 2010.

IPCC - Intergovernamental Panel on Climate Change. Emissions from livestock and manure management. In: Eggleston, H. S.; Buendia, L.; Miwa, K.; Ngara, T.; Tabane, K. (eds). IPCC Guideliness for nacional greenhouse gas inventories. Hayama: IGES, 2006. p. 747846.

IPCC - Intergovernmental Panel on Climate Change. Climate Change 2001: The Scientific Basis-Contribution of Working Group 1 to the IPCC Third Assessment Report. Cambridge Univ. Press. 2001. Disponível em: <http://www.grida.no/publications/other/ipcc_tar/?src=/climate /ipcc_tar/wg1/index.htm> Acesso em: abril. 2012.

LANA, G.R.Q; ROSTAGNO, H.S.; ALBINO, L.F.T.; LANA, A.M.Q. Efeito da temperatura ambiente e da restrição alimentar sobre o desempenho e a composição da carcaça de frangos de corte. Rev. bras. zootec., 29(4):1117-1123, 2000.

LIMA, M.A; CABRAL, O.M.R; MIGUEZ, J.D.G. Mudanças climáticas globais e a agropecuária brasileira. Embrapa Meio Ambiente, Jaguariúna - SP, 397p. 2001.

LIMA, M.A. Agropecuária Brasileira e as mudanças climáticas globais: caracterização do problema, oportunidades e desafios. Cadernos de Ciência \& Tecnologia, Brasília, v.19, n. 3, p.451-472, set./dez. 2002.

MACHADO, F.S; PEREIRA, L.G.R; GUIMARAES JUNIOR, R.; LOPES, F.C.F.; CHAVES, A.V.; CAMPOS, M.M; MORENZ, M.J.F. Emissões de metano na pecuária: conceitos, métodos de avaliação e estratégias de mitigação. Juiz de Fora: Embrapa Gado de Leite. 2011. 92p (Documentos 147).

MEDEIROS, L.F.D; VIEIRA, D.H. Apostila de Bioclimatologia animal I. UFRJ e IZ, 1997. Disponível em http://www.iz.ufrrj.br/zootecnia draa/Biblioteca/ Fernando/Apostila\%20de\%20Bioclimatologia\%20I.pdf Acesso em abril 2012. 
MOSIER, A., WASSMANN, R., VERCHOT, L., KING, J.; PALM, C. Methane and nitrogen oxide fluxes in tropical agricultural soils: sources, sinks and mechanisms. Environment, Development and Sustainability, 6(1-2): 11-49, 2004.

MURRAY, R. M.; BRYANT, A. M.; LENG, R. A. Rates of production of methane in the rumen and large intestines of sheep. British Journal Nutrition, v. 36, p. 1-14, 1976.

OLIVEIRA, P. A. V. de. Tecnologias para o manejo de resíduos na produção de suínos: manual de boas práticas. Embrapa Suínos e Aves, Concórdia - SC, 109 p, 2004.

PRIMAVESI, O.; FRIGHETTO, R.T.S.; PEDREIRA, M. S.; LIMA, M.A.; BERCHIELLI, T.T.; BARBOSA, P.F. Metano entérico de bovinos leiteiros em condições tropicais brasileiras. Pesq. agropec. bras., Brasília, v.39, n.3, p.277-283, mar. 2004.

SARDA, L.G.; HIGARASHI, M.M.; MULLER, S.; OLIVEIRA, P.A.; COMIN, J.J. Redução da emissão de $\mathrm{CO}_{2}, \mathrm{CH}_{4}$, e $\mathrm{H}_{2} \mathrm{~S}$ através da compostagem de dejetos suínos. R. Bras. Eng. Agríc. Ambiental, v.14, n.9, p.1008-1013, 2010.

SILVA, I.J.O; PANDORFI, H.; ACARARO JUNIOR, I.; PIEDADE, S.M.S; MOURA, D.J. Efeitos da climatização do curral de espera na produção de leite de vacas holandesas. R. Bras. Zootec., v.31, n.5, p.2036-2042, 2002.

THOMAS, C.D.; CAMERON, A.; GREEN, R.E.; BAKKENES, M.; BEAUMONT, L.J.; COLLINGHAM, C.Y.; ERASMUS, B.F.N.; SIQUEIRA, M.F. de; GRAINGER, A.; HANNAH, L.; HUGHES, L.; HUNTLEY, B.; JAARSVELD, A.S. van; MIDGLEY, G.F.; MILLES, L.; ORTEGA-HUERTA, M.A.; PETERSON, T.A.; PHILLIPS, L.O.; WILLIANS, S.E. Extinction risk from climate change. Nature, v.427, p.145-148, 2004.

USDA. UNITED STATES DEPARTMENT OF AGRICULTURE. Foreign Agricultural Service (FAS). Market and Trade Data: trade reports archives. 2011. Disponível em: http://www.fas.usda.gov/livestock_arc.asp. Acesso em: abril. 2012. 